\title{
Smile Design with All Ceramic Veneers
}

\author{
${ }^{1}$ Dileep Soni, ${ }^{2}$ Deepak Raisingani, ${ }^{3}$ Ashwani B Prasad, ${ }^{4}$ Prachi Mital, ${ }^{5}$ Harshit Srivastava, ${ }^{6}$ Abhilasha Dixit
}

\begin{abstract}
The use of porcelain laminate veneers to solve esthetic and/or functional problems has been shown to be a valid management option, especially in the anterior esthetic zone. In cases when patients decline orthodontic treatment, adhesively bonded porcelain veneers are a reliable treatment option to modify the appearance of tooth position and form, to close diastema or cervical embrasures, or to change the tooth shade. Porcelain veneers are one of the best corrective options available considering biological, functional, mechanical, and esthetic points of view. The present case report is about discolored anterior teeth in a healthy dentition by means of sectional porcelain veneers simply cemented onto the natural teeth and with minimal tooth preparation.
\end{abstract}

Keywords: Esthetics, Porcelain veneers, Smile design.

How to cite this article: Soni $D$, Raisingani $D$, Prasad AB, Mital $\mathrm{P}$, Srivastava H, Dixit A. Smile Design with All Ceramic Veneers. J Mahatma Gandhi Univ Med Sci Tech 2017;2(1):51-54.

\section{Source of support: Nil}

Conflict of interest: None

\section{INTRODUCTION}

At the present time, many dentists are performing veneers as a routine procedure. They have become an indispensable part of the esthetic dentistry. Many veneering procedures can be done with little tooth preparation, and usually, anesthesia is not required. It is important for the dentist to understand that this technique is in its infancy, and many changes in the years to come will evolve and improve it. There is, however, a requirement of the profession for having more knowledge about this treatment option. This permanent technique provided an alternative for those who wanted an improvement in their smiles without the need of undergoing extensive crown preparations. Ceramic veneers have various range of longevity from a few months to several years and have

\footnotetext{
${ }^{1,4,5}$ Senior lecturer, ${ }^{2}$ Professor and Head, ${ }^{3}$ Reader, ${ }^{6}$ Resident (2nd Year)

${ }^{1-6}$ Department of Conservative Dentistry and Endodontics Mahatama Gandhi Dental College \& Hospital, Jaipur, Rajasthan India

Corresponding Author: Abhilasha Dixit, Resident (2nd Year) Department of Conservative Dentistry and Endodontics Mahatama Gandhi Dental College \& Hospital, Jaipur, Rajasthan India, Phone: +919828549303, e-mail: abhilasha.dxt@ gmail.com
}

been diversified in their esthetic characteristics. ${ }^{1}$ As early as 1937, Pincus developed thin facings made of air-fired porcelain. He tried improving the appearance of the Hollywood actors for their close-up photographs by attaching these thin labial porcelain veneers temporarily with denture adhesive powder. Pincus was fully aware of the importance of the "Hollywood smile" as an integral part of the image and public opinion. These facings gave a feasible option to the full crown for the actors, who needed to change their smile provisionally, yet they possessed very little strength, and the technology necessary to provide a permanent means of attaching the veneers to tooth structure was lacking. Porcelain veneers are a recent and very exciting development in the dental armamentarium. They allow a transition in the appearance, color, size, spacing, and also positioning of the teeth to some extent. ${ }^{2}$

\section{CASE REPORT}

A 57-year-old man complained about the appearance of his upper anterior teeth. He needed correction in the shape and size of teeth and the midline diastema closed (Fig. 1). After discussing with the patient, porcelain veneers were planned on teeth 13 and 23. We wanted to have a conservative approach to execute the treatment plan and fulfill the patient's desires. ${ }^{3}$

After ensuring that the patient is a good candidate for porcelain laminate veneer treatment, it is crucial that a complete oral examination is done to make sure that the veneer therapy is appropriately chosen.

The appointment records must have

- Preoperative intra- and extraoral photographs

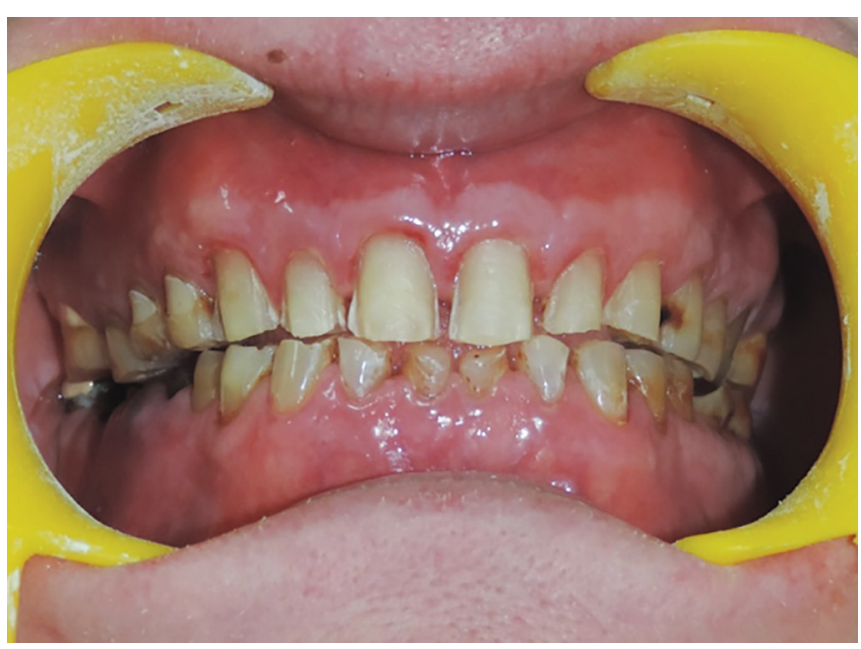

Fig. 1: Preoperative view 


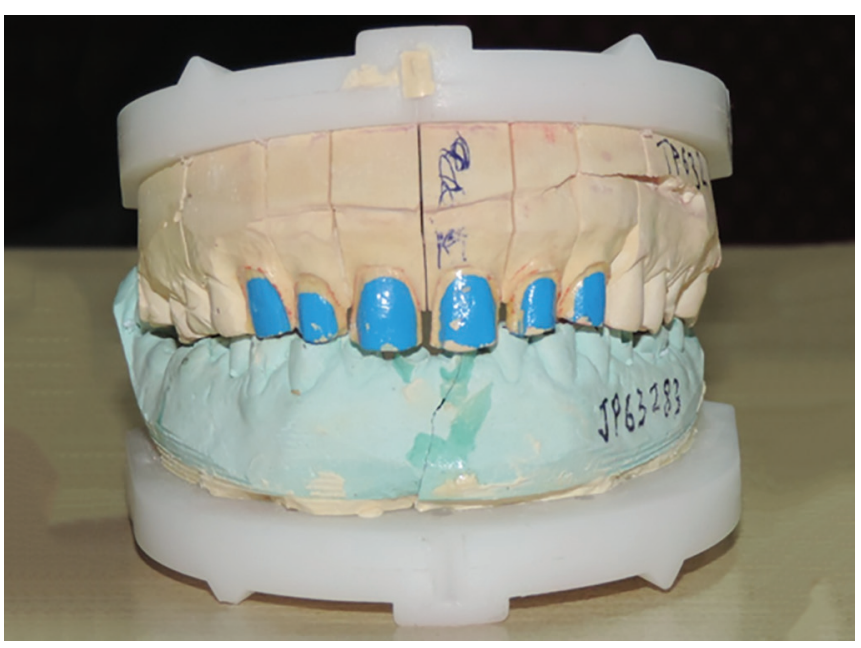

Fig. 2: After tooth preparation on cast

- Periodontal probing of the entire oral cavity

- Decayed, missing, filled teeth index is noted

- Complete hard and soft tissue examination

- Existing occlusion is checked

- Impressions of maxillary and mandibular arches for study model fabrication

- Bite registration; a face bow transfer used for mounting on an articulator

- Patient's interview regarding goals and expectations ${ }^{4}$ This information is not only essential for the dentist to evaluate how appropriate the planned treatment is, but it also provides the guideline to develop the treatment plan and prognosis. The treatment planning was discussed with the patient.

\section{TOOTH PREPARATION FOR VENEERS}

The goal is to remove a uniform layer of the tooth structure:

- Using burs with calibrated diamond rings

- Reducing diagnostic steps

- Intrinsic principle is to recreate the initial form and function

The preparations must satisfy the following four basic principles of functional, biological, and esthetic integration to be achieved: stabilization, reinforcement, retention, and adhesion. Relying only on adhesion without considering the other three factors may lead to failure either immediately or later. Preserving as much of the natural enamel as possible, although desirable, must never jeopardize the planned restoration by minimizing the preparation. Enamel reduction requires special instrumentation that involves the four surfaces of the teeth. ${ }^{5-7}$

After patient's consent, shade selection was done using vitapan classical shade guide (Vita Zahnafabrik, Germany). Then the tooth preparation was completed. Final shade was selected and impression was made using single-step double-mix technique using addition silicone

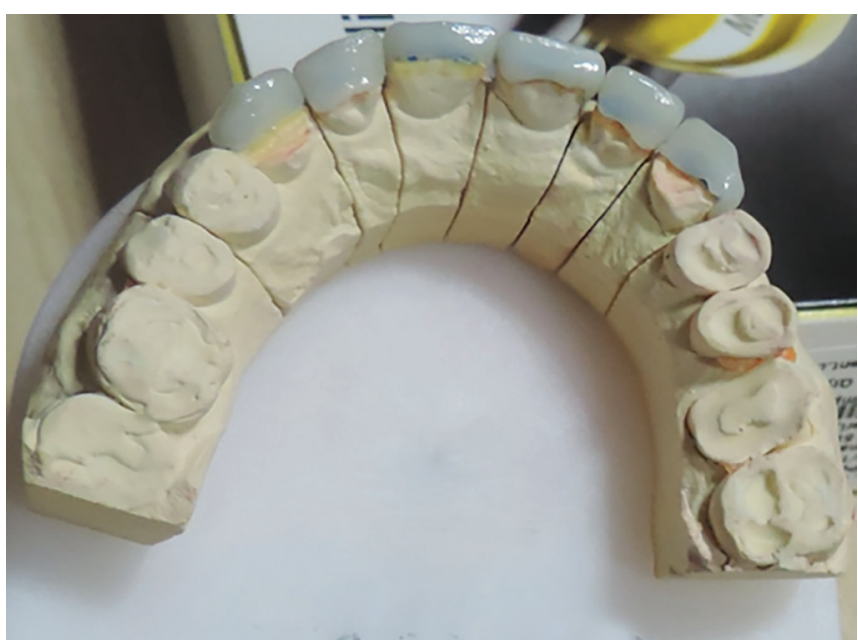

Fig. 3: All ceramic veneers on dental cast-lingual view

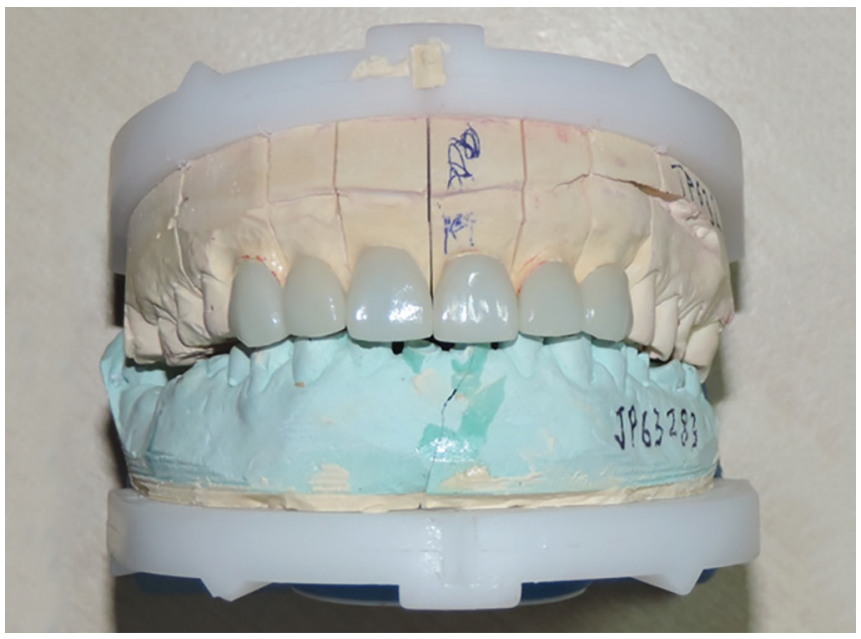

Fig. 4: All ceramic veneers on dental cast-labial view

putty and light body consistency (Dentsply Aquasil) impression technique, a prefabricated perforated tray was loaded with putty and at the same time light body material was syringed around the prepared teeth to record the fine details and the previously loaded tray was inserted in the mouth to make impressions. The impression was poured in type IV gypsum product and die preparation was done. Temporary restoration was fabricated meanwhile. The porcelain veneers (IPS e.max) were laboratory fabricated (Figs 2 to 4). The trail of the veneer was done for the shade, fit, marginal adaptation, shape, size, symmetry, and contacts. Then, under proper isolation, veneers were cemented onto the prepared tooth using self-curing resin-based luting cement (Multilink Automix, Ivoclar vivadent) and extra cement was removed (Fig. 5).

\section{DISCUSSION}

\section{Instrumentation}

Throttle position sensor (TPS) kit comprises eight burs that were used to enable veneer preparations. The laminate veneer preparation kit (Fig. 6) comprises 


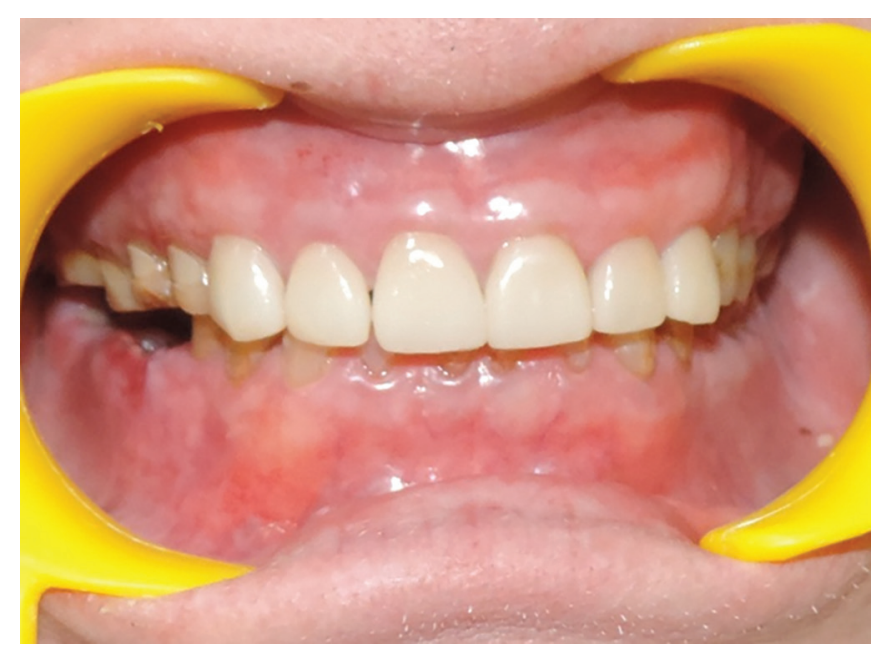

Fig. 5: Postoperative view

- Two instruments (gauges TFC1 and TFC2) to monitor labial reduction;

- Two instruments (TFC3 and TFC4) for reduction of enamel and margins;

- Two instruments (TFC5 and TFC6) for occlusal reduction;

- Two finishing instruments (TFC7 and TFC8).

Brasseler TPS tool kit is provided with instruments for preparation and finishing of ceramic veneers.

The two "depth-cutter" instruments (TFC1, TFC2) are used to guide, visualize, and quantify enamel reduction. The rounded tip can be used to plot the margins. It has been considered dangerous by the authors to gauge reduction in enamel depth between 0.5 and $0.1 \mathrm{~mm}$ without depth guide. They also recommend two instruments based on the same principle in the laminate veneer preparation kit, both of them are designed considering the same concern. Specifically designed porcelain laminate veneer preparation and finishing kits ease the whole procedure, since the chosen burs can be used step by step. Other techniques exist for monitoring depth, such as those advocated before the introduction of penetration gauges. A spherical diamond bur (Komet H01 314 009) traces out a 0.4 to $0.5 \mathrm{~mm}$ groove as a guide in the same way as Lusco's enamel depth cutter (a small diamond disk with a smooth stop). ${ }^{8,9}$ Uniform enamel preparation must result in an average tissue reduction of $0.5 \mathrm{~mm}$. One may, in cases of extreme discoloration, be inclined to increase the depth to 0.7 to $0.8 \mathrm{~mm}$. A depth below $0.3 \mathrm{~mm}$ is not recommended (Goldstein).

- Enamel provides a better seal and more effectively diminishes marginal leakage than a finish line in either cementum or glass ionomer.

- Due to relatively thin enamel in gingival, half the desired reduction in that area is $0.3 \mathrm{~mm}$.

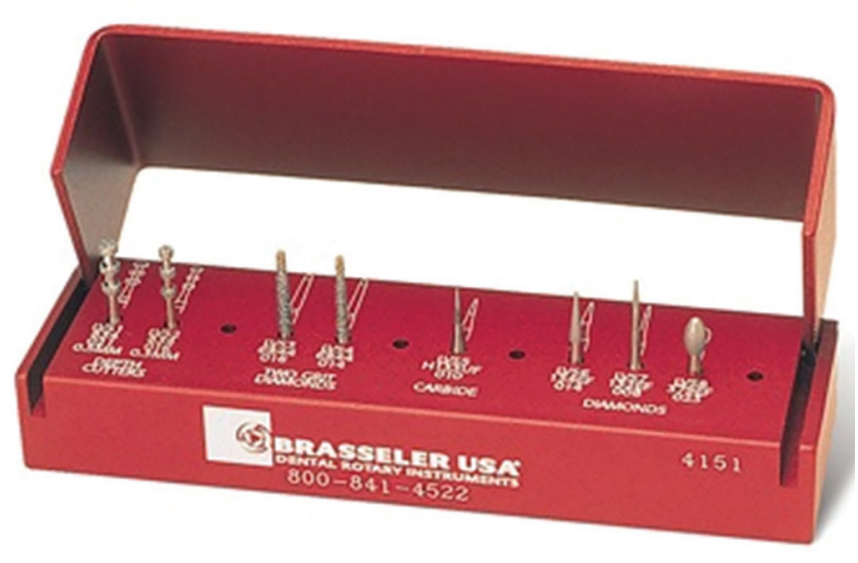

Fig. 6: Porcelain kit

- Porcelain laminate veneer has minimum thickness of 0.3 to $0.5 \mathrm{~mm}$

\section{Cementation}

Cementation procedures for bonding veneers:

- Cementation is a crucial step in the process of ensuring the retention, marginal seal, and durability of indirect restorations.

- Either adhesive or nonadhesive cementing procedure can be followed. Adhesive cementation involves the use of an agent to promote bonding of the restorative material to the substrate; it is a combination of adhesive chemical bonding and micromechanical interlocking.

- A luting agent is used in nonadhesive (conventional) cementation, to cover the space between the restoration and the natural tooth and relies entirely on micromechanical retention. ${ }^{10-12}$

\section{Step 1: IPS e.max Restoration Conditioning}

- Etching Restoration: Apply IPS Ceramic Etching Gel (5\% HF acid) for 20 seconds to bonding surface of the restoration. (This procedure achieves surface area, which in turn increases micromechanical retention.)

- Rinse thoroughly and keep it dry.

- The clinician places silane over the etched surface to increase the wettability of the resin cement and to interact chemically with both the resin matrix and the hydroxylated porcelain surface.

Some investigators have reported higher veneer failure rates when ceramic is air abraded and silanated but not etched with HF acid, thus both etching and silanation are recommended. The surface is best cleaned with CoJet (ESPE). The $30 \mu \mathrm{m}$ thickness of the material will still let the $80 \mu \mathrm{m}$ of the adhesive (Optibond) that has been applied at the preparation stage stay in place. Gingival bleeding 
should not be caused. ${ }^{9}$ A diode laser (Biolase) can be used to recontour the gingiva, if needed.

- Priming Restoration: Apply Monobond Plus Universal Primer to the bonding surface of the restoration. Allow to react for 60 seconds and then completely air dry.

\section{Step 2: Tooth Conditioning}

- Etching Tooth: Apply total etch 37\% phosphoric acid etching gel (15 seconds on dentin, 30 seconds on enamel). Rinse and dry leaving prepared surface moist.

- Priming Tooth: Apply bonding agent to moist the preparation.

\section{Step 3: Cementation}

- Mix and dispense cement into the restoration.

- Adhesive cementation to enamel or dentin requires the use of an adhesive system, followed by application of resin cement.

- Adhesive systems can be either self-etching or total etching. ${ }^{13}$

\section{Step 4: Clean-up}

- After seating, each quarter surface is light cured for 1 to 2 seconds. The cement will achieve a gel-like consistency for easy clean-up.

\section{Finishing and Polishing}

Excess resin cement needs to be removed upon completion of the cementation. Initial removal from the gingival and the interproximal areas can be achieved with a \#12 scalpel blade. The use of modern dental materials and a justifiable reliance on the predictable artistic abilities of the dental technologist allows the fabrication of both esthetic and durable restorations. ${ }^{14}$

\section{CONCLUSION}

Past clinical experience and almost 30 years of data show that porcelain laminate veneers are very predictable and successful when the porcelain laminate veneer is bonded to enamel. ${ }^{1}$ The current best practice in use of porcelain laminate veneer for creating an esthetic change is to use a very minimal, noninvasive tooth preparation that is restored with a very thin piece of porcelain. Porcelain laminate veneers are a versatile treatment option and can prove to be a solution to many problems, but they may not always be the best solution. Appropriate decision and good communication are the keys to victory with porcelain laminate veneer therapy. ${ }^{1,2}$

\section{REFERENCES}

1. Christensen GJ. Veneering of teeth. State of the art. Dent Clin N Am 1985 Apr:29(2):373-391.

2. Radz GM. Minimum thickness anterior porcelain restorations. Dent Clin North Am 2011 Apr;55(2):353-370.

3. Christensen GJ. Veneering teeth with ceramic has become a major part of esthetic dentistry, and many general dentists provide this service. JADA 20062006 Dec;137(12):1721-1723.

4. Calamia JR, Calamia CS. Porcelain laminate veneers: reasons for 25 years of success. Dent Clin N Am 2007;51:399-417.

5. Freedman, GA.; Mc Laughlin, GL. Color atlas of porcelain laminate veneers. 1st ed. St. Louis: Ishiyaku Euro America; 1990.

6. Reshad M, Cascione D, Magne P. Diagnostic mock-ups as an objective tool for predictable outcomes with porcelain laminate veneers in esthetically demanding patients: A clinical report. J Prosthet Dent 2008 May;99(5):333-339.

7. D'Arcangelo C, De Angelis F, Vadini M, D'Amario M, Caputi S. Fracture resistance and deflection of pulpless anterior teeth restored with composite or porcelain veneers. J Endod 2010 Jan;36(1):153-156.

8. Radz GM. Minimum thickness anterior porcelain restorations. Dent Clin North Am 2011 Apr;55(2):353-370.

9. Matinlinna JP, Vallittu PK. Bonding of resin composites to etchable ceramic surfaces - an insight review of the chemical aspects on surface conditioning. J Oral Rehabil 2007 Aug;34(8):622-630.

10. Cekic I, Ergun G, Lassila LV, Vallittu PK. Ceramic-dentin bonding: effect of adhesive systems and light-curing units. J Adhes Dent 2007 Feb;9(1):17-23.

11. Kanehira M, Finger WJ, Hoffmann M, Komatsu M. Compatibility between an all-in-one self-etching adhesive and a dual-cured resin luting cement. J Adhes Dent 2006 Aug;8(4): 229-232.

12. Pegoraro TA, da Silva NR, Carvalho RM. Cements for use in esthetic dentistry. Dent Clin N Am 2007 Apr;51(2):453-471, x.

13. Radovic I, Monticelli F, Goracci C, Vulicevic ZR, Ferrari M. Self-adhesive resin cements: a literature review. J Adhes Dent 2008 Aug;10(4):251-258

14. Manso AP, Silva NR, Bonfante EA, Pegoraro TA, Dias RA, Carvalho RM. Cements and adhesives for all-ceramic restorations. Dent Clin North Am 2011 Apr;55(2):311-332. 